\title{
Chapter 23 \\ Climate Change Adaptation and Societal Transformation: What Are the Public Health Challenges?
}

\author{
Virginia Murray and Tim Chadborn
}

\begin{abstract}
Behavioural change with societal transformation has been the key processes whereby hand and respiratory hygiene, social distancing and self-isolation that citizens across the world have been asked to implement to respond to the global COVID-19 pandemic. Is it possible to use such societal transformation approaches to change our behaviour for climate change adaptation? The European Commission (EC) funded research and innovation programmes that will be launched from 2021 will mobilise investment and EC's wide efforts to achieve measurable and time-bound goals on issues that affect citizens' daily lives. These programmes are based around five missions, one of which is the Mission on Adaptation to climate change including societal transformation. This will provide an opportunity to build evidence-informed assessment and design of interventions and should use a systems approach to determine and deploy the most cost-effective mix of public health behaviour change policy options according to the Nuffield Intervention Ladder and the Behaviour Change Wheel. This will maximise the likelihood of delivering societal transformation actions through ambitious but realistic research and innovation activities to help deliver planetary health programmes for Europe more widely.
\end{abstract}

Keywords Climate change adaptation - Societal transformation · Planetary health $\cdot$ Health behavioural change models

\section{The European Commission's Missions for Horizon Europe}

As part of the EC's budget for 2021-2027, the Commission proposed on 7 June 2018 that the next EC research and innovation programme, Horizon Europe, should have a proposed budget of $€ 100$ billion (European Commission 2018). By addressing

\footnotetext{
V. Murray ( $\square)$

FRCP, FRCPath, FFPH, FFOM, Head of Global Disaster Risk Reduction, UK Health Security Agency, London, UK e-mail: Virginia.Murray@phe.gov.uk

T. Chadborn

Head of Behavioural Insights and Evaluation Lead, UK Department of Health and Social Care, London, UK

e-mail: Tim.Chadborn@dhsc.gov.uk

(C) The Author(s) 2022

Climate Adaptation Modelling, Springer Climate,

https://doi.org/10.1007/978-3-030-86211-4_23
} 
important societal challenges, such as climate change, through ambitious but realistic research and innovation activities, the European Commission (EC) has chosen to make clear to citizens how they can make a real difference in their lives, and in wider society as a whole (European Commission 2019a, b).

Missions are one of the main novelties of Horizon Europe and they were designed to boost the impact of EC-funded research and innovation by mobilising investment and EC's wide efforts around measurable and time-bound goals around issues that affect citizens' daily lives. To achieve their ambition the EC has organised five missions with one addressing adaptation to climate change including societal transformation.

In addition, the European Commission report on 'Adaptation to Climate Change-Related Health Effects - Scientific Advice to Strengthen the Resilience of the European Health Sector in View of Climate Change' states that there is a need to seek and prioritise synergies with climate mitigation actions and disaster risk reduction (European Commission 2020). It goes on to state that embedding 'human health' as a key component of the EU adaptation strategy should be aligned with the Sustainable Development Goals and with the Sendai Framework for Disaster Risk Reduction. This report recommends that there is a need to use the entire mix of policy interventions available at the EC level to intensify adaptation efforts in general, and particularly, the integration of health into climate adaptation.

\section{Societal Transformation}

UNESCO reports that 'the world is undergoing important social transformations driven by the impact of globalization, global environmental change and economic and financial crises, resulting in growing inequalities, extreme poverty, exclusion and the denial of basic human rights. These transformations demonstrate the urge for innovative solutions conducive to universal values of peace, human dignity, gender equality and non-violence and non-discrimination. Young women and men, who are the most affected by these changes, are hence the principal key-actors of social transformations' (UNESCO 2019).

The COVID-19 pandemic represents a massive global health crisis. It has required large-scale behaviour change with societal transformation. To make such changes, the pandemic has placed and continues to place significant psychological burdens on individuals to help align human behaviour with the recommendations of epidemiologists and public health experts.

To address climate change - the other great challenge of our generation-it is apparent that the challenges associated with the application with societal transformation and adaptation models needed further consideration if evidence-based policy and decision-making in public and private sectors were to be effective. As a member of the Adaptation to climate change including societal transformation Mission, we identified the need for research to deliver the societal transformation that will engage all and recommended doing this using health behavioural change models. 
This paper addresses some of the considerations around climate change drivers, recognises that societal transformation could limit the global average temperature rise, reflects what systems thinking for interventions might be available and finally how research might deliver evidence for the suggested interventions.

\section{The Climate Change Driver}

The global climate crisis is an existential threat to the world as we know it. Without a radical abatement of greenhouse gases, global warming will reach and exceed $3-4^{\circ}$ before the end of the century (European Commission 2020). Climate change has already made some weather and climate extremes more frequent and severe. In 2019, the Lancet Countdown reports that the life of every child born today will be profoundly affected by climate change, with populations around the world increasingly facing extremes of weather, food and water insecurity, changing patterns of infectious disease and a less certain future. Without accelerated intervention, this new era will come to define the health of people at every stage of their lives (Watts et al. 2019). The COVID-19 pandemic has taught a lesson about how closely environmental, societal and human health are connected.

A second path — which limits the global average temperature rise to "well below 2 ${ }^{\circ} \mathrm{C}$ ' - is possible and would transform the health of a child born today for the better, throughout their lives. Placing health at the centre of this coming transition will yield enormous dividends for the public and the economy, with cleaner air, safer cities and healthier diets.

Bold new approaches to policymaking, research and business are needed to change course. An unprecedented challenge demands an unprecedented response. It will take the work of the 7.5 billion people currently alive to ensure that the health of a child born today is not defined by a changing climate.

\section{Working Towards the 'Second Path' to Limit the Global Average Temperature Rise to 'Well Below $2{ }^{\circ} \mathrm{C}$ '}

By identifying the key strategies to invest in for adaptation to climate change with societal transformation is briefly summarised as planetary health processes such as:

Enhancing early warning for extreme weather events and their cascading and complex hazards and risks (behaviour change and resilience especially for people at high risk such as with chronic obstructive pulmonary disease).

Emphasising the value of active travel and public transit (reducing exposure and minimising the production of vehicle fumes).

Reducing outdoor (e.g. coal power station outputs) and household air pollution (e.g. wood-burning stoves). 
Encouraging sustainable and healthy diets (e.g. reducing meat consumption).

Reducing the use of fossil fuels and plastics.

Building sustainable and healthy cities.

\section{What Systems Thinking Approaches for Interventions are Available?}

Public Health England and its partners use the latest behavioural science to tackle the problems of complexity, focusing on developing multidimensional approaches to support healthy behaviours (PHE 2019). The PHE Strategy 2020-2025 recognises that behaviour occurs in a system and that we need to address multiple factors that influence behaviour and the behaviours of multiple actors at different levels of the system (e.g. for wood burning: citizens; retailers and manufacturers of wood burners; retailers of alternative electric heaters etc.).

The Interventions Ladder of Bioethics (Nuffield 2007) and Behaviour Change Wheel (Michie et al. 2011) frameworks can help plan by describing the degree of possible government intervention (with the most directive at the top to the least directive at the bottom) and categorising the methods that can be used to intervene: legislation, regulations, fiscal measures, guidelines, service provision, communications, media networks and marketing, environmental/social planning (such as building cycle routes/supporting social movements). Using a combination of complementary methods, a planned and synergistic systems approach to deliver the desired goals efficiently and equitably can be considered, for example:

Eliminate Choice: e.g. Legislate to stop highly polluting vehicles entering urban areas.

Restrict Choice: e.g. Regulate with standards for approved wood burners in smokeless zones.

Guide choice: e.g. Fiscal Measures to increase the cost of fuel to shift purchases towards electric vehicles.

Guide choices by incentives: e.g. offering tax-breaks for the purchase of bicycles for travel to work.

Guide choices by changing the default policy: e.g. by encouraging more restaurants to provide vegetarian-only cuisines.

Enable choices: e.g. enable individuals to change their behaviour by building cycle lanes.

Provide information: e.g. campaigns by encouraging the reduced use of plastic carrier bags.

Do nothing or simply monitor the current situation.

Recognising that behaviour change is critical for adaptation to climate change, we must improve understanding of the key behaviours involved in driving change, the key influencing those behaviours and what mix of interventions works best to 
Fig. 23.1 Behaviour Change Wheel (Michie et al. 2011)

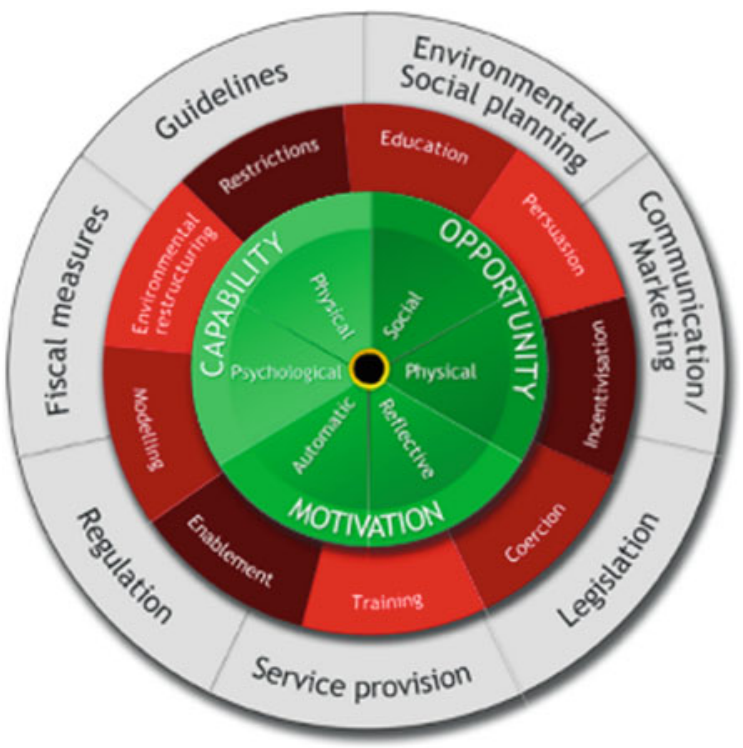

achieve impact. Most importantly, we need to use validated frameworks to ensure that our interventions are designed to target the key influences on behaviour based on evidence and theory and that we consider and utilise the full range of options available to us.

The Behaviour Change Wheel can help to address this by:

Developing behaviour change interventions from scratch,

Building on or modify existing interventions and choosing from existing or planned interventions (Fig. 23.1).

The Behaviour Change Wheel involves a number of processes to achieve and these include:

\section{Assessment.}

Evaluating the appropriateness of existing or proposed interventions in terms of the 'APEASE' criteria: Acceptability, Practicability, Effectiveness, Affordability, Side-effects, and Equity (Annex 1).

\section{Behaviour selection.}

Identifying and selecting key behaviours to focus on in order to achieve policy objectives.

\section{Capability, opportunity and/or motivation (COM-B) diagnosis.}

What will most likely bring about the desired behaviour-in terms of changes in the target group's capability, opportunity and/or motivation to engage in/stop the behaviour. 


\section{Selecting intervention types.}

Identifying the broad types of intervention matched to the COM-B diagnosis: education, persuasion, incentivization, coercion, training, environmental restructuring, modelling, and enablement.

\section{Formulating an implementation strategy.}

Choosing how to deliver interventions using: legislation, service provision, fiscal measures, guidelines, environmental/social planning, comms/marketing, and/or regulation.

\section{Constructing the intervention.}

Deciding the details of the intervention content and delivery.

The Behaviour Change Wheel and associated frameworks can be used alongside checklists from behavioural economics such as MINDSPACE (Annex 2) to ensure that we consider the key biases and heuristics that affect people's behaviour and keep these insights in mind when we design interventions and policy (Cabinet Office 2014).

\section{How Research Might Deliver Evidence for the Suggested Interventions}

To maximise the chances of success, it will be important to adopt a researchfocused and systems-thinking approach such as the paper on building the case for systems thinking about climate change and mental health (Berry et al. 2018). Systems mapping with stakeholders and systematic reviews of the quantitative and qualitative evidence will collate what we already know about the behaviours, their influences and who performs them in each part of the complex climate change system. It will also integrate the evidence of which interventions have worked, and not, in the past, to what extent, for whom, to what cost, and in what context (real-world and research interventions).

Systems mapping and evaluation also need to be applied to existing policies and interventions so that we develop a comprehensive understanding of what we are already doing, where are the gaps and opportunities and where to focus resourcesas informed by the understanding about the behaviours above. This can identify the need for new interventions or the need to enhance the behaviour change content or delivery of existing interventions. For each intervention, it will be critical to engage in detailed monitoring and evaluation to assess the impact. For example, the Public Health England Heatwave Plan and its annual reviews is an example of such monitoring and evaluation (CCC 2018). 


\section{Conclusions and Recommendations}

The COVID-19 pandemic represents a massive global health crisis. Behavioural change with societal transformation has been the key processes whereby control measures of effective hand and respiratory hygiene, social distancing and selfisolation that have been implemented by citizens across the world have been asked to implement to respond to the global COVID-19 pandemic. Is it possible to use such societal transformation approaches to change our behaviour for climate change adaptation?

The recommendations from the Mission on Adaptation to climate change including societal transformation provide an opportunity to build evidence-informed assessment and design of interventions. By using a systems approach to determine and deploy the most cost-effective mix of policy options according to the intervention ladder and the Behaviour Change Wheel will assist in delivering societal transformation actions through ambitious but realistic research and innovation activities. These EC-funded research and innovation programmes that will be launched from 2021 will mobilise investment and EC's wide efforts around measurable and time-bound goals around issues that affect citizens' daily lives.

This approach should help to lead us to a future where the planetary health processes that are so vital for the future and summarised in Fig. 23.2 are the new normal.

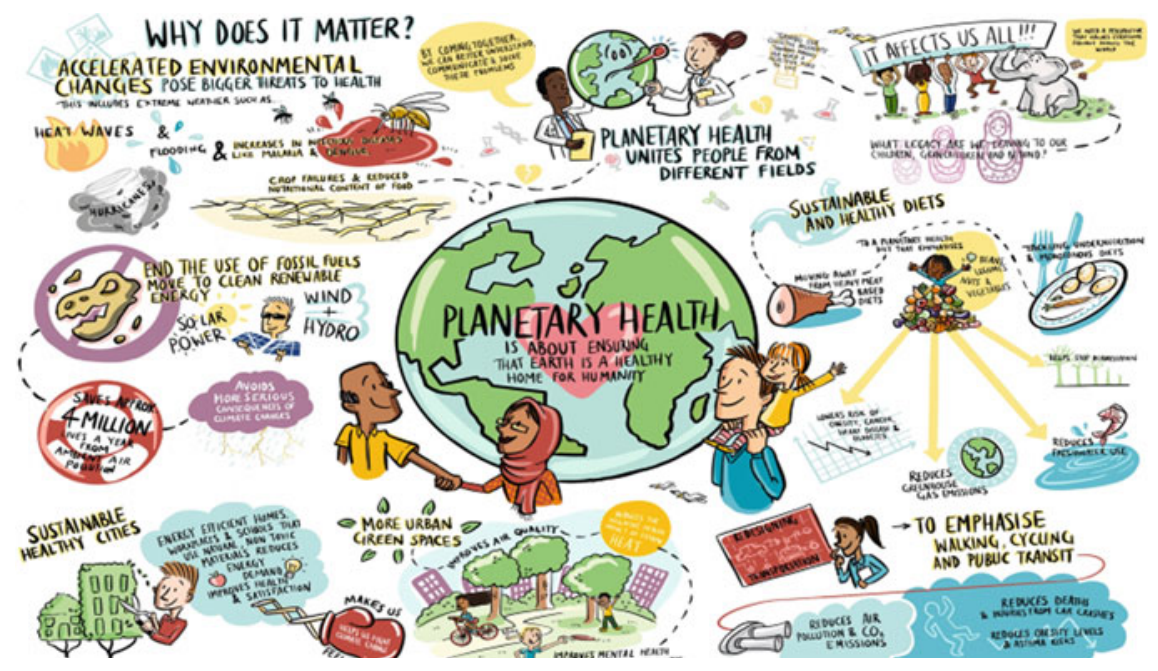

Fig. 23.2 Planetary Health cartoon Wellcome Trust (2019) 


\section{Annexe 1 MINDSPACE is a Checklist of Influences on Our Behaviour for Use When Making Policy (Cabinet Office 2010)}

Messenger: we are heavily influenced by who communicates information.

Incentives: our responses to incentives are shaped by predictable mental shortcuts such as strongly avoiding losses.

Norms: we are strongly influenced by what others do.

Defaults: we 'go with the flow' of pre-set options.

Salience: our attention is drawn to what is novel and seems relevant to us.

Priming: our acts are often influenced by sub-conscious cues.

Affect: our emotional associations can powerfully shape our actions.

Commitments: we seek to be consistent with our public promises and reciprocate acts.

Ego: we act in ways that make us feel better about ourselves.

\section{Annexe 2 The APEASE Criteria for Assessing Interventions, Intervention Components and Ideas (Michie et al. 2014)}

\begin{tabular}{l|l}
\hline Acceptability & $\begin{array}{l}\text { How far is it acceptable to key stakeholders? This includes the target group, } \\
\text { potential funders, practitioners delivering the interventions and relevant } \\
\text { community and commercial groups }\end{array}$ \\
\hline Practicability & $\begin{array}{l}\text { Can it be implemented at scale within the intended context, material and human } \\
\text { resources? What would need to be done to ensure that the resources and } \\
\text { personnel were in place, and is the intervention sustainable? }\end{array}$ \\
\hline Effectiveness & $\begin{array}{l}\text { How effective is the intervention in achieving the policy objective(s)? How far } \\
\text { will it reach the intended target group and how large an effect will it have on } \\
\text { those who are reached? }\end{array}$ \\
\hline Affordability & $\begin{array}{l}\text { How far can it be afforded when delivered at the scale intended? Can the } \\
\text { necessary budget be found for it? Will it provide a good return on investment? }\end{array}$ \\
\hline Side-effects & $\begin{array}{l}\text { What are the chances that it will lead to unintended adverse or beneficial } \\
\text { outcomes? }\end{array}$ \\
\hline Equity & $\begin{array}{l}\text { How far will it increase or decrease differences between advantaged and } \\
\text { disadvantaged sectors of society? }\end{array}$ \\
\hline
\end{tabular}




\section{References}

Berry HL, Waite TD, Dear KBG, Capon AG, Murray V (2018) The case for systems thinking about climate change and mental health Nature Climate Change 8:282-290. https://doi.org/10.1038/ s41558-018-0102-4)

Cabinet Office and Institute of Government Policy (2010) MINDSPACE Influencing behaviour through public policy. https://www.instituteforgovernment.org.uk/sites/default/files/publicati ons/MINDSPACE.pdf. Accessed 6 Dec 2019

Directorate-General for Research and Innovation (European Commission), Group of Chief Scientific Advisors (European Commission 2020) Adaptation to health effects of climate change in Europe. https://op.europa.eu/en/web/eu-law-and-publications/publication-detail/-/pub lication/e885e150-c258-11ea-b3a4-01aa75ed71a1 accessed on 22 July 2020

European Commission (2018) EU budget: Commission proposes most ambitious Research and Innovation programme yet. https://ec.europa.eu/commission/presscorner/detail/en/IP_18_4041. Accessed 22 July 2020

European Commission (2019a) Commission launches work on major research and innovation missions for cancer, climate, oceans and soil. https://ec.europa.eu/info/news/commission-lau nches-work-major-research-and-innovation-missions-cancer-climate-oceans-and-soil-2019-jul04_en. Accessed 22 July 2020

European Commission (2019b) Mission area: Adaptation to climate change including societal transformation. https://ec.europa.eu/info/horizon-europe-next-research-and-innovation-framew ork-programme/mission-area-adaptation-climate-change-including-societal-transformation_en. Accessed 22 July 2020

European Commission (2020) Accelerating the transition to a climate prepared and resilient Europe - Interim report of the mission board for adaptation to climate change, including societal transformation. https://op.europa.eu/en/web/eu-law-and-publications/publication-detail/-/public ation/1d5234b9-b68a-11ea-bb7a-01aa75ed71a1. Accessed 22 July 2020

Michie S, van Stralen MM, West R (2011) The behaviour change wheel: a new method for characterising and designing behaviour change interventions. Implementation Sci 6:42. https://doi.org/ 10.1186/1748-5908-6-42

Michie S, Atkins L, West R (2014) The APEASE criteria for designing and evaluating interventions. In: The Behaviour Change Wheel: A Guide to Designing Interventions. London: Silverback Publishing. http://www.behaviourchangewheel.com/. Accessed 8 Dec 2019

Nuffield Council on Bioethics Public health: ethical issues 2007. https://nuffieldbioethics.org/ass ets/pdfs/Public-health-ethical-issues.pdf. Accessed 5 Dec 2019

Public Health England Strategy 2020-2025 (2019). https://assets.publishing.service.gov.uk/ government/uploads/system/uploads/attachment_data/file/831562/PHE_Strategy_2020-25.pdf. Accessed 8 Dec 2019

UNESCO (2019) Social transformations. https://en.unesco.org/themes/social-transformations. Accessed 22 July 2020

UK Committee on Climate Change (CCC) (2018) Heat and Preventable Deaths in the Health and Social care System. https://www.theccc.org.uk/wp-content/uploads/2019/07/Outcomes-Heat-pre ventable-deaths-case-study.pdf. Accessed 8 Dec 2019

Watts N, Amann M, Arnell N et al (2019) The 2019 report of the Lancet Countdown on health and climate change. Lancet 394:1836-1878. https://www.thelancet.com/journals/lancet/article/ PIIS0140-6736(19)32596-6/fulltext. Accessed 8 Dec 2019 
Open Access This chapter is licensed under the terms of the Creative Commons Attribution 4.0 International License (http://creativecommons.org/licenses/by/4.0/), which permits use, sharing, adaptation, distribution and reproduction in any medium or format, as long as you give appropriate credit to the original author(s) and the source, provide a link to the Creative Commons license and indicate if changes were made.

The images or other third party material in this chapter are included in the chapter's Creative Commons license, unless indicated otherwise in a credit line to the material. If material is not included in the chapter's Creative Commons license and your intended use is not permitted by statutory regulation or exceeds the permitted use, you will need to obtain permission directly from the copyright holder.

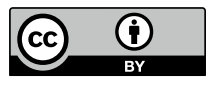

